\title{
José María López Piñero (1933-2010), gran maestro
}

\section{Esteban Rodríguez Ocaña (*)}

(") Historia de la Ciencia. Universidad de Granada

Dynamis

[0211-9536] 2011; 31 (1): 227-231

Vaya por delante la expresión de todo mi respeto, mi admiración y mi reconocimiento para quien, con Pedro Laín, ha sido el principal forjador de la disciplina de Historia de las Ciencias, desde su sección de Historia de la Medicina, en España. Por su inmenso trabajo, su infatigable contribución a la colectividad intelectual, por las tres generaciones de estudiosos formados junto a él. Por sus libros de texto, tan claros y tan ponderados. Por sus diccionarios biográficos, indispensables y, dentro de su inevitable caducidad, por haber sido los primeros realizados con un sentido moderno de la erudición. Por sus incansables bibliografías. Por sus iconografías de objetos científicos. Por su prosa clara y elegante. Por su ejercicio modelo de universitario, abierto al mundo. Por su curiosidad universal.

Conocí a José María López Piñero como miembro del Tribunal de mi oposición al Cuerpo de Profesores Adjuntos que se celebró en Madrid en el otoño de 1981. Quiero decir que ese momento fue la primera vez que lo saludé y conversé con él, porque su compañía intelectual no me había abandonado prácticamente desde que inicié mi contacto con la cátedra de Historia de la Medicina en 1976. En particular, los capítulos escritos por él en la Historia Universal de la Medicina, (Laín Entralgo, ed. Barcelona, 197275) -la principal obra de consulta con la que preparé el segundo ejercicio de aquellas oposiciones, el temario de clases y lección a exponer- fueron un auténtico deslumbramiento, por su claridad expositiva, su frescura narrativa y por la cantidad de implicaciones que encerraban casi cada una de sus frases; me resultaron particularmente atractivas sus exposiciones sobre la Iatroquímica de la segunda mitad del XVII y, en especial, la Patología romántica en la Europa latina, que desde entonces ha constituido mi tema 
preferido en la docencia de cursos generales de Historia de la Medicina. El tercer ejercicio de aquellas oposiciones consistió en el análisis de un texto de John Huglings Jackson, un autor al que López Piñero había dedicado una monografía (John Hughlings Jackson (1835-1911): evolucionismo y neurología. Madrid, 1973) que, desgraciadamente, yo no había leído con la suficiente atención, si bien recordaba algunas de sus conclusiones doctrinales, que pude incluir en mi comentario.

No hay que olvidar que la primera influencia de López Piñero en mi vida profesional actuó a través de personas interpuestas, puesto que Luís García Ballester y Guillermo Olagüe, ambos procedentes del grupo forjado en la Facultad valenciana, fueron mis mentores inmediatos en Granada. Los contenidos de las clases impartidas en esta procedían en gran medida del magisterio del profesor murciano-valenciano, sazonado, por supuesto, con las aportaciones de ambos. La imagen de entrega, perseverancia, dominio bibliográfico y generosidad intelectual con que evoco mis primeros recuerdos sobre José María es deudora, sobre todo, de los relatos sobre la actividad en Valencia. El contacto incluso frenético con la bibliografía hispana de la materia de cara a la oposición pronto reveló a un gigante, por su fecundidad literaria y su universalidad de intereses, por su agudeza y por su excelente estilo narrativo. Y quiero creer que varios de los rasgos peculiares de la docencia practicada en Granada, en especial la relevancia de los seminarios, rara avis en una Facultad de grupo único y clase magistral para más de 300 alumnos, son herederos de la práctica docente valenciana, posiblemente moldeada por las estancias de José María en Munich, Bonn y Zürich, en este último caso con Edwin Ackerknecht, uno de los discípulos directos de Sigerist.

El segundo episodio en el que nos relacionamos ambos fue con motivo de la celebración en 1984 de las pruebas de idoneidad para el área de Historia de la Ciencia, la medida de excepción con la que la Ley de Reforma Universitaria buscó acabar con el problema de los PNN a través de una única convocatoria no presencial. Compartimos el tribunal, que López Piñero presidía, otros cuatro profesores de historia de la medicina (Prof. Granjel, Paniagua y Girón, junto conmigo; los dos granadinos éramos los últimos llegados como numerarios de la disciplina) y otros dos de historia de la farmacia (Valverde López y Herrero). Las discusiones en torno al nivel exigible y los distintos curricula fueron clarificadoras respecto a la distancia que separaba la práctica historiográfica en lo que se llamaba «la escuela valenciana» de otras tradiciones académicas, en términos de rigor, 
exigencia y obligaciones. No digamos en materia de conexión internacional. Lo que no quita para que aparecieran entre los seniors ciertos rasgos atrabiliarios, cuando menos sorprendentes para un recién llegado como era yo en aquel momento.

Como metodólogo, José María se sentía hijo de la etapa dorada de la Historia de la Medicina, heredero de Sigerist y Diepgen, y joven compañero de Ackerknecht o Rosen, con quien compartió tareas directivas en la Academia Internacional de Historia de la Medicina. El suyo era un positivismo sano, defensor de los beneficios del progreso, pero a años-luz del positivismo vulgar, ese antiquariat que nos llenaba de sabios de campanario. En sus estudios sobre el desarrollo de las ciencias médicas había incorporado la necesidad de completar el análisis puramente doctrinal o de las ideas, finamente contextualizadas en su medio filosófico y religioso, con las perspectivas etnológica more Ackerknecht y sociológica more Rosen. Pero resultó alérgico a otros desarrollos posteriores; en particular, criticaba la charlatanería en la que, en su opinión, caían los críticos postmodernos, incluyendo el feminismo académico. Los problemas historiográficos había que solucionarlos, a su entender, mediante la búsqueda de fuentes y el análisis profundo de las recuperadas con la pluralidad de métodos cualitativos y cuantitativos que habían aportado la historia cultural clásica y la historia social. El linguistic turn en sus términos no significaba otra cosa que recurrir al análisis semántico-documental aportado por el estudio de la documentación científica. Creo que, en el fondo, José María sabía que no llevaba razón y que ninguna posición intelectual en la historia puede considerarse imperfectible; de ahí su tolerancia para admitir o cobijar orientaciones plurales.

Pero la discusión del método no ha sido una tarea a la que López Piñero haya dedicado mucho tiempo; la tenía como una preocupación secundaria en su trabajo. De las varias publicaciones específicas me complace sacar a colación su ensayo de 1971 sobre el lugar posible de la historia en los estudios médicos (Hacia una ciencia sociomédica. Medicina Española, 1971; 65: 13-22) que, a mi parecer, denota una enorme lucidez estratégica; me sorprendió advertir su paralelismo con las propuestas bastante posteriores de Alfons Labisch (Zur Sozialgeschichte der Medizin. Methodologische Überlegungen und Forschungsbericht. Archiv für Sozialgeschichte, 1980; 20: 431-469).

Su elección por crear la Historia de la Ciencia dentro del catálogo de áreas de conocimiento post LRU, pese a sus declaraciones en otro sentido (véase el relato de Emilio Balaguer y Rosa Ballester en el reciente número 
de Medicina e Historia dedicado a la memoria de su maestro) y a su definición explícita sobre la tarea de la Historia de la Medicina (estupendamente expuesta en la introducción a su Historia de la medicina, Madrid, 1990), a mi me habla de su relativa incomodidad con la complejidad social de la medicina y con su dimensión sociopolítica. De hecho, sus materiales de trabajo han sido exclusivamente impresos de autoría científica o médica; el material de archivo no le atrajo lo más mínimo, incluso en algún lugar apuntó a que su consulta le había inducido a error (Los modelos de investigación historicomédica y las nuevas técnicas. Historia de las ciencias, A. Lafuente y J. J. Saldaña, eds. Madrid, 1987, p. 139). De política, López Piñero, como contestaba a los periodistas que le han entrevistado con motivo de alguna efeméride cultural en los últimos tiempos, no hablaba.

De entre su larguísima obra, 364 títulos reseñados con su nombre en la base de datos bibliográfica del Instituto Universidad-CSIC que lleva su nombre, Bibliografía Histórica de la Ciencia y de a Técnica en España, http://www.ihmc.uv-csic.es/buscador.php (consultada el 10 de marzo de 2011), recordaré ahora sólo algunos. De la serie de ediciones de clásicos, la «Colección de textos de la Salud pública» que dirigió para el Ministerio de Sanidad y Consumo a mediados de la década de 1980 resulta especialmente cercana a una de mis líneas preferentes de trabajo, y colaboré en ella por gentil voluntad de su director con uno de sus volúmenes. El ambicioso programa, incluyendo 30 volúmenes ordinarios y varios más complementarios, quedó inconcluso por avatares editoriales; José María lo retomó en cuatro entregas publicadas en Revista Española de Salud Pública en 2006. Seguramente una abismal diferencia en nuestra instalación social como investigadores universitarios en España respecto a la de nuestros colegas de otros países radica en la escasez de oferta editorial para dar salida a nuestros proyectos. Incluso a personas tan autorizadas, rigurosas y cumplidoras como López Piñero el soporte editorial le jugó malas pasadas; no hay más que recordar la rara factura de su gran reformulación del renacimiento hispano, Ciencia y técnica en la sociedad española de los siglos XVI y XVII (Barcelona, 1979), impreso sin notas.

Goza de gran éxito en la docencia su recolección Medicina, historia, sociedad: antología de clásicos médicos (Barcelona, 1973), como demuestra su reedición, por la editorial Triacastela, como Antología de clásicos médicos, en 1998.

Y de su interés por la recuperación de clásicos, es destacable, como rasgo de modernidad, su atención a la historia de la iconografía científica 
hispànica, produciendo un buen número de ediciones monográficas, desde el Atlas de Crisóstomo Martínez (Valencia, 1964) o la selección de grabados de El arte de navegar en la España del Renacimiento (Barcelona, 1979; 1986) a La imagen del cuerpo humano en la medicina moderna (siglos XVI-XX) (Valencia, 1999), entre otras contribuciones. Una preciosa antología es $E l$ grabado en la ciencia hispánica (Madrid, 1987), donde las ilustraciones, a gran formato, se acompañan de cortos textos que sitúan autor y obra en su contexto inmediato.

El último elemento de su obra que quiero subrayar ahora es su vocación por la historia regional, convertida en seña de identidad de su grupo de trabajo. A mi parecer procede de una interpretación exacta de las obligaciones sociales de la Universidad, si se quiere que sea un ente vivo ligado a su entorno. Su estancia como colegial becado en el CM Beato Juan de Ribera y, posteriormente el periodo de director del Colegio Mayor Luis Vives, a mediados de la década de 1960, le permitió establecer una sólida red de contactos intelectuales y sociales en la comunidad valenciana que le han servido, sin duda, como elemento facilitador en esta tarea de la historia regional. Su arraigo valenciano se muestra en su pertenencia al Consell Valencià de Cultura entre 1985 y 1992 y, tras su jubilación, a la Cátedra de Eméritos de la Comunidad Valenciana, desde donde ejerció una intensa labor como editor, además de recibir el nombramiento como Hijo Adoptivo de la ciudad de Valencia. También fue cooptado a la Academia de la Historia en 2007.

La gran virtud de José María ha sido la de dar acogida y estímulo a un desarrollo plural de la historia de la medicina, presidido por esa propuesta, reiterada en sus textos, de «ocuparnos de la medicina en toda su complejidad» y que se manifiesta no solamente en el trabajo de tres generaciones de discípulos directos sino en el de la enorme mayoría de los profesionales actuales. Por eso, todos somos discípulos suyos y a todos nos afecta su pérdida. 
